\title{
Aggression and anxiety trait level of young male contact and noncontact athletes
}

\author{
Petra Pačesová* and Pavel Šmela \\ Faculty of Physical Education and Sports, Comenius University in Bratislava, Bratislava, Slovakia
}

Copyright: ( 2020 P. Pačesová and P. Šmela. This is an open access article licensed under the Creative Commons Attribution License (https://creativecommons.org/licenses/by/4.0/).

\begin{abstract}
Background: It is necessary to deal with the aggressive behaviour of young people and find out whether sport can play a role in this area. So far, findings indicate modification role of sports activity and its type in terms of contact's occurrence, in the behavior of individuals. Objective: The aim of the study is to compare the level of the dimension of aggression and anxiety trait between nonathletes and contact and noncontact sport athletes and to assess the relationship between dimensions of aggression and the level of anxiety trait across the groups. Methods: The research group consisted of 153 males aged $22.07 \pm 2.49$ years: 47 contact sport athletes, 51 noncontact sport athletes and 55 nonathletes. Dimensions of aggression were evaluated by the Buss-Perry Aggression Questionnaire, anxiety trait was evaluated by the State-Trait Anxiety Inventory. The differences between the groups were assessed with the Kruskal-Wallis test and Mann-Whitney $U$ test was used for posthoc pairwise comparisons. Relationship between dimensions of aggression and anxiety trait was assessed by the Spearman correlation coefficient. Results: We found that nonathletes were more physically aggressive than contact sport athletes and they also displayed a higher level of anger and hostility. Moreover, nonathletes were more hostile, physical and verbally aggressive than noncontact sport athletes. Nonathletes also had a higher level of anxiety trait than athletes. There was no difference between athletes in any dimension of aggression and anxiety trait level. Besides that, we found a significant relationship between anxiety trait level and physical aggression across the groups. Conclusion: Our findings suggest that sports activity can be beneficial for personality in both contact and noncontact athletes. Sport activity may be one of the factors which increase the possibility of releasing of aggression, while "contactness" of the sport does not play any major role in the aggression of athletes.
\end{abstract}

Keywords: dimensions of aggression, behaviour, combat sport, sports activity, sport psychology

\section{Introduction}

Aggressive behaviour may (or may not) occur in human behavior, it depends on the situation and level of aggressivity as a personality predisposition. Aggressivity could be defined as a tendency to behave or act aggressively and it is part of the personality (Anderson \& Bushman, 2002). In scientific literature, the General Aggression Model is described as a comprehensive, integrative, framework for understanding aggression. It says that the aggressive response is affected by input factors such a personality and situation characteristics, but also the interaction of cognitive and affective

\footnotetext{
* Address for correspondence: Petra Pačesová, Department of Sports Educology and Sports Humanistic, Faculty of Physical Education and Sports, Comenius University in Bratislava, Nábr. arm. gen. L. Svobodu 9, 81469 Bratislava, Slovakia. E-mail: petra.pacesova@uniba.sk
}

dispositions of an individual (Allen, Anderson, \& Bushman, 2018; Anderson \& Bushman, 2002).

Aggression in sport is in general defined by Kerr (1999) as an intentional hurting of the opponent, which exceeds the limits set by the rules of a specific type of sport. Slepička, Hošek, and Hátlová (2009) differentiate the groups of specific sports from the point of view of aggressive behavior appearance: sports where aggression is an essential part of sports performance (combat sports), sports where aggression is not part of sports performance, but it may appear (e.g., football, basketball), sports in which is not expected an increased level of aggression, but may appear rarely (e.g., cycling, athletics), sports, that do not allow direct physical contact (e.g., swimming, tennis, volleyball) and aesthetic-coordinating sports (e.g., figure skating, synchronized swimming, gymnastics).

Scientific studies focused on aggression in sports divide it into instrumental and hostile type. 
Instrumental aggression in sport is manifested as a physical injury which means the way to win the competition. Hostile aggression is different, its primary aim is to cause injury to the opponent (Caron, Halteman, \& Stacy, 1997). The existence of hostile aggression in contact sports is more common than in the noncontact sport (Boostani \& Boostani, 2012). It was shown that aggressive sport behavior is associated with „contactness" in male sports (Conroy, Silva, Newcomer, Walker, \& Johnson, 2001).

According to Fabio and Towey (2018), Kuśnierz, Cynarski, and Litwiniuk (2014), Malinauskas, Dumciene, and Malinauskiene (2014) or Ziaee, Lotfian, Amini, Mansournia, and Memari (2012), nonathletes have a higher level of aggression in comparison with contact and noncontact sport athletes.

However, some studies have not shown any differences in the level of aggression between athletes and nonathletes (Filho, Ribeiro, \& Garcia, 2005; Keeler, 2007; Khan, Fazaldad, Waheed, \& Arif, 2017).

We can consider contact sport activity as one of the factors which reduce the possibility of ventilation of aggression in an improper way (Kotarska, Nowak, Szark-Eckardt, \& Nowak, 2019). On the other hand, some studies have shown contradictory findings - the higher level of aggression of athletes than nonathletes, regardless of the contactness of sport disciplines (e.g., Chandler, Johnson, \& Carroll, 1999; Fletcher \& Dowell, 1971). Also, Boostani and Boostani (2012) claim that contact sport athletes have a higher level of anger, physical aggression and hostility than noncontact sport athletes and nonathletes.

From the above mentioned findings it seems that it is important to evaluate various dimensions of aggression independently.

Anxiety trait is a personal predisposition to experience more frequent and more intense anxiety symptoms (Stewart, Taylor, \& Baker, 1997). From the scientific literature, it is not clear if we can expect a higher or lower level of anxiety traits in athletes compared to nonathletes. Study of Mladenović, Lazarević, Trunić, Bogavac, and Živković (2016) has shown that nonathletes have a higher level of anxiety trait than athletes. On the contrary, Bostani and Saiiari (2011) have shown a higher level of anxiety symptoms in athletes compared to nonathletes.

According to Kunimatsu and Mersee (2012), there seems to be a unique relationship between anxiety and the different forms of aggression. Even in the context of personality, anxiety-related disorders are often characterized by impaired social behaviours such as excessive aggression and violence (Neumann, Veenema, \& Beiderbeck, 2010). However, anxiety may be associated with aggression in common life situations and situations in sport as well (e.g., a racing situation may act as a stimulus to cause anxiety and anxiety about failure may increase aggressive behavior (Besharat \& Ghiabi, 2012; Lazarus, 2000). According to Gümüșdağ (2013), hostile aggression in athletes (professional football players) is associated, among other things, also with anxiety trait. Egawa et al. (2020) have in this context considered as important, that sport activity seems to be a tool, which may help lower anxiety symptoms.

Based on the variety of previous results, specifically in the level of aggression between athletes and nonathletes as well as between athletes according to "contactness" of their sport disciplines, it is necessary to devote attention to this research area henceforth.

The main aim of this study was to assess differences in the level of physical and verbal aggression, anger, hostility and anxiety trait in various groups of athletes and nonathletes. Another aim was to assess the relationship between dimensions of aggression and anxiety trait.

\section{Methods}

\section{Participants}

The research group consisted of 153 healthy male subjects from 18 to 27 years of age. The group of contact sport consisted of 47 male combat sports athletes (age $21.79 \pm 1.90$ years), the group of noncontact sports consisted of 51 athletes (age $22.33 \pm 2.72$ years). Karate, judo and box were considered as contact sports, athletics and cycling were assumed to be noncontact ones. All athletes underwent 8 hours of training per week on average. The group of non-athletic individuals consisted of 55 males (age $22.05 \pm 2.71$ years) and they did not engage in any continuous sports training. A snowball sampling was used to recruit three groups of nonathletes, contact and noncontact athletes.

\section{Measurement and procedure}

Dimensions of aggression were evaluated by the Buss-Perry Aggression Questionnaire (BPAQ; Buss \& Perry, 1992). For the evaluation of the anxiety trait, the State-Trait Anxiety Inventory (STAI) was used. The internal consistency coefficients $\alpha$ for each scale are adequate: .85 for physical aggression, .72 for verbal aggression, .83 for anger, .77 for hostility (Buss \& Perry, 1992) and between .86 and .90 for anxiety trait scale (Ruisel, 1980).

\section{BPAQ}

The level of aggression-related dimensions was measured by the 29-item self-report questionnaire (Buss \& Perry, 1992). The Slovak version of the questionnaire was based on its validated Czech version using the 
reverse translation method. The translation was done by two independent experts in the field of psychology.

Structural analyses of the Questionnaire have revealed four underlying factors: Physical Aggression, Verbal Aggression, Anger, and Hostility, yielding a minimum score of 29 points and a maximum score of 145. All items are answered using a 5-point scale format ranging from 1 (extremely unusual for me) to 5 (extremely typical for me).

Specifically, a high score in dimension physical aggression indicates a lack of ability to control physical aggression, high scores in verbal aggression indicate that the individual has a greater tendency to be more argumentative, high scores in anger are generally associated with irritability, frustration, and emotional lability and high scores in hostility indicate attitudes of paranoia, bitterness and social isolation (Healey, Holmes, Curry, Seto, \& Ahmed, 2019).

\section{STAI}

Level of anxiety trait was measured using the STAI questionnaire developed by Spielberger, Gorsuch, and Lushene (1970, Slovak standardisation by Ruisel, 1980). The standardised questionnaire is based on two independent scales: anxiety state and anxiety trait scale. In our research, we used only the anxiety trait scale. This scale is designed to measure trait anxiety as a characteristic or tendency while respecting "individual differences in the tendency to perceive the world, the disposition to respond in a specific and predictable manner, individual differences in the expression of special emotional states and the positive correlation between the strength of personality and the intensity of the corresponding emotional state" (Ruisel, 1980, p. 36-37). The result for the scale is a whole number obtained by totalling the scale values (taking account of reversal scoring). The higher the score means a higher level of anxiety trait.

In our research sample the internal consistency (calculated by Cronbach's $\alpha$ indices) for the dimensions of BPAQ was .80 for physical aggression, .77 for verbal aggression, .72 for anger, .74 for hostility and .82 for the anxiety trait as a dimension of STAI questionnaire.

All participants voluntarily participated in the study. Data were collected by a psychologist (the first author of this study). The study design was approved by the Ethics Committee of the Faculty of Physical Education and Sport of Comenius University in Bratislava. Data were collected with the informed consent of the subjects.

\section{Statistical analysis}

Statistical comparison was performed using SPSS software (Version 23 for Windows; IBM, Armonk, NY, USA). The Shapiro-Wilk test did not confirm the normality of the data. For the assessment the effect of group we used Kruskal-Wallis tests. Differences between individual groups were assessed using the Mann Whitney $U$ test. The effect size of the differences was assessed by $\eta^{2}$ (Pierce, Block, \& Aguinis, 2004) and $r$ coefficient (Pett, 1997). The magnitude of the $\eta^{2}$ was evaluated in the following ranges: $\eta^{2} \geq .26$ (large effect), $\eta^{2}=.03-.25$ (medium effect), $\eta^{2} \leq .02$ (small effect); of the $r$ coefficient in ranges: $r \geq 5$ (large effect), $r=.3-.5$ (medium effect), $r=.1-.3$ (small effect). Spearman correlation coefficient was used to assess the relationship between the level of aggression dimensions and anxiety trait. The significance level was set at .05 for all statistical tests.

\section{Results}

Table 1 presents received score in each dimension of aggression and anxiety trait of male athletes and nonathletes. Intergroup comparison revealed significant effect of group in all dimensions of aggression: physical aggression $\left(p=.001, \eta^{2}=.086\right)$, verbal aggression $\left(p=.049, \eta^{2}=.048\right)$, anger $\left(p=.028, \eta^{2}=.048\right)$, and hostility level $\left(p<.001, \eta^{2}=.127\right)$. There was a significant effect of group in the level of anxiety trait as well $\left(p=.001, \eta^{2}=.090\right)$. Pairwise comparisons showed, that between nonathletes and noncontact sport athletes is a significant difference in physical aggression $(p=.037, r=.203)$ and verbal aggression $(p=.015$, $r=.236$ ), while nonathletes have a significantly higher level of physical and verbal aggression compared to noncontact sport athletes. There was also a significant difference in the level of hostility $(p=.002, r=.294)$,

Table 1

Scores for dimension of aggression and anxiety trait (mean $\pm S D$ ) of male athletes and nonathletes

\begin{tabular}{lccccc}
\hline & $\begin{array}{c}\text { Physical } \\
\text { aggression }\end{array}$ & $\begin{array}{c}\text { Verbal } \\
\text { aggression }\end{array}$ & Anger & Hostility & Anxiety trait \\
\hline Nonathletes & $3.10 \pm 0.93$ & $3.34 \pm 0.94$ & $3.09 \pm 0.85$ & $3.11 \pm 0.80$ & $50.47 \pm 11.12$ \\
Noncontact sport athletes & $2.67 \pm 0.99$ & $2.84 \pm 0.93$ & $2.89 \pm 0.60$ & $2.59 \pm 0.82$ & $44.35 \pm 12.66$ \\
Contact sport athletes & $2.45 \pm 0.75$ & $3.10 \pm 0.96$ & $2.69 \pm 0.71$ & $2.39 \pm 0.81$ & $42.09 \pm 10.55$ \\
\hline
\end{tabular}


with higher hostility of nonathletes. There was no significant difference in the level of anger between nonathletes and noncontact sport athletes $(p=.121$, $r=.150$ ). In addition, nonathletes had a higher level of anxiety trait compared to noncontact athletes $(p=.011, r=.246)$.

Comparison of contact sports athletes and nonathletes showed also several significant differences. According to our results nonathletes were significantly more physically aggressive than contact sport athletes $(p<.001, r=.379)$ and they also can be characterized by a higher level of anger ( $p=.015, r=.241)$ and hostility ( $p<.001, r=.407)$. There was no significant difference in verbal aggression $(p=.274, r=.108)$. Level of anxiety trait was significantly lower in contact sport athletes compared to nonathletes $(p<.001, r=.363)$.

Comparison of contact and noncontact sports athletes showed no significant difference in physical aggression $(p=.328, \quad r=.099)$, verbal aggression $(p=.178, r=.136)$, anger $(p=.113, r=.160)$, hostility ( $p=.247, r=.117)$, neither in the level of anxiety trait $(p=.475, r=.072)$.

The results of the correlation analysis are presented in Table 2. A positive relationship in the group of noncontact sport athletes was demonstrated between the level of anxiety trait and physical aggression and verbal aggression. In the group of contact sport athletes, there was a significant relationship between the level of anxiety trait and physical aggression and anger as well. The highest number of significant correlations was found in the group of nonathletes, specifically between the level of anxiety trait and physical aggression, verbal aggression and anger as well. This indicates a significant positive relationship between the level of anxiety trait and physical aggression in all groups of participants.

\section{Discussion}

Today's society considers some of the manifestations of aggression to be unacceptable. Therefore, it is necessary to find a socially acceptable alternative to ventilate aggression. In this context, sport may be an appropriate way (Gill \& Williams, 2000; Trulson, 1986). In our study both contact and noncontact sportathletes have lower aggression in comparison with nonathletes. This finding is in accordance with the studies by Ziaee et al. (2012), Kuśnierz et al. (2014) or Fabio and Towey (2018). But, in terms of contactness of sport disciplines, there was no difference between our groups of athletes. Keeler (2007) also came to similar findings in her study.

A possible explanation can be according to Khan et al. (2017) that, sports generally may be the institution which teaches its followers to practice patience and tolerance.

Combat sports and martial arts as contact sport disciplines, have a special educational potential in the area of shaping positive behavior patterns and transmitting moral values which could help reduce aggression (Kotarska et al., 2019). This may be the reason why we found the lowest level in most dimensions of aggression in contact athletes.

Malinauskas et al. (2014) examined the level of aggression of male adolescents practicing various sports. Our results do not correspond with their findings that nonathletes are less verbally aggressive and less angry than athletes. Our study showed the highest level of anger right in the group of nonathletes, nonathletes' verbal aggression was significantly higher compared to noncontact athletes only. In Malinauskas et al. (2014) research it turned out, that combat athletes were the angriest group, which is inconsistent with our results.

Our findings do not correspond with the findings of Boostani and Boostani (2012) as well. According to the authors, contact sport athletes (kick-box athletes) have a higher level of anger, physical aggression and hostility than other athletes (swimmers and karate athletes) and nonathletes. Moreover, their results showed that, except of kickbox athletes, other sports groups (swimmers and karate athletes) are not distinctive in different dimensions of aggression from nonathletes. A possible explanation may be that, karate as a sport discipline causes offloading energy and excitement and

Table 2

Correlation between the level of anxiety trait and dimensions of aggression of male athletes and nonathletes

\begin{tabular}{lcccc}
\hline & $\begin{array}{c}\text { Physical } \\
\text { aggression }\end{array}$ & $\begin{array}{c}\text { Verbal } \\
\text { aggression }\end{array}$ & Anger & Hostility \\
\hline Nonathletes & $.595^{* *}$ & $.393^{* *}$ & $.271^{*}$ & .191 \\
Noncontact sport athletes & $.833^{* *}$ & $.320^{*}$ & .074 & .101 \\
Contact sport athletes & $.613^{* *}$ & .160 & $.290^{*}$ & .113 \\
\hline
\end{tabular}

Note. ${ }^{*} p<.05,{ }^{* *} p<.01$. 
causes to decrease from aggressive behaviors (Boostani \& Boostani, 2012).

Findings of research of Reynes and Lorant (2001) showed a higher level of aggression in its individual dimensions (except for the dimension of anger) of nonathletes in compare to athletes engaged in combat sport and martial arts. Our results correspond with this finding except for the dimension of anger - we found a higher level of anger in nonathletes in compare to contact sport athletes. Also, it follows that it is important to pay attention to the anger of athletes. It turns out, that anger rumination plays an important role not only in aggression (both physical and verbal), but in hostility as well (Anestis, Anestis, Selby, \& Joiner, 2009).

As Ahmadi, Besharat, Azizi, and Larijani (2011) claim, anger is an effective factor on athlete's aggression. The identification of this psychological structure in athletes can be considered as the first step toward preventing aggressive behaviour. The preparation of training and interfering programs for decreasing anger and increasing its management especially in the contact sports is one of the ways to moderate the level of athlete's anger (Ahmadi et al., 2011).

Among athletes and nonathletes varies the level of anxiety trait as well. Our study showed a higher level of anxiety trait in nonathletes, in comparison to athletes. These results confirmed the findings of Mladenovic et al. (2016). So there is a further question - if sport is related to a person's anxiety trait level. According to the study of Aidar et al. (2018), sports activity may seem to be a tool to reduce the symptoms of anxiety. On the contrary, research of Ali, Aseem, and Hussain (2019) did not show any difference in the level of anxiety trait after six weeks of anaerobic sports activity. Despite the ambiguous results of the studies, it is necessary to deal with the level of anxiety trait of athletes, because it can lead to athlete's burnout (Cho, Choi, \& Kim, 2019), and according to our results, it can be linked to physical aggression.

In terms of personality variables, it is interesting to notice the significant relationship between the level of dimensions of aggression and anxiety trait. According to Kunimatsu and Mersee (2012), there is a link between anxiety and the different forms, functions, and subtypes of aggression. Our research has partially confirmed this finding - it revealed a positive significant relationship between anxiety trait and level of physical aggression and anger in contact sport athletes. In noncontact sport, athletes exist similar relationship - between anxiety trait and level of physical and verbal aggression. The highest number of significant relationships was found in the group of nonathletes, specifically between anxiety trait and physical and verbal aggression and anger. In summary, in all groups of participants, the positive significant relationship between anxiety trait and physical aggression was found.

Our results showed a lower level of aggression of contact sport athletes in several aggression dimensions, in compare to nonathletes, we found the positive relationship between anger and anxiety trait in contact sport too. A possible explanation may be that negative emotions, such anger, may lead to aggression (Berkowitz, 1989; Wyckoff, 2016).

Although this research did not answer the question whether sports activity reduces the level of anxiety trait, it has pointed out the existence of a positive relationship between some of the dimensions of aggression and anxiety trait, which extends knowledge in this research area.

Despite this study's interesting findings in the area of aggression of contact sport, noncontact sport athletes and nonathletes, it has several limitations that should be acknowledged. Firstly, the size of the research group of athletes and nonathletes in our research was relatively small. We can also generalize these results only for a narrow group of population. Also, the BPAQ questionnaire is not validated in the Slovak language. It would be also beneficial to repeat this research under the conditions of new standardized psycho-diagnostic tools measuring the level of aggression and anxiety trait.

We assume that the specificity which contact sport has in relation to aggression (especially philosophy of combat sports as a contact sport or sports training as ventilation of aggression in a proper way) may lead to the lower level of aggression in compare to nonathletes. However, we can only considerthese causes as a dominant and cannot confirm them without further research focused on these specific variables.

It is believed that sport activity is one of the most critical extracurricular activities for young people as they teach the rules and disciplines. However, the effects of sports participation on development are still controversial (Lee \& Lim, 2019). Based on the acquired data it can seem that regular sport activity might have beneficial effects on the level of aggression and anxiety trait. However, further studies with the quasi-experimental or longitudinal design are needed to clarify the role of sport activity in areas of psychological variables.

\section{Conclusions}

We may assume that sport activity (and it does not matter if it is a contact or noncontact sports activity) may be one of the factors which increases the possibility 
of ventilation of aggression in the appropriate way namely, athletes dispose of the lower level of physical aggression and hostility. Nonathletes have a higher level of anxiety trait than both groups of athletes. The anxiety trait is also positively associated with physical aggression. The type of sports discipline (based on contactness) does not play any major role in the aggression or anxiety trait of athletes.

\section{Acknowledgments}

The authors wish to thank everyone who participated in the study.

\section{Conflict of interest}

There were no conflicts of interest.

\section{References}

Ahmadi, S. S., Besharat, M. A., Azizi, K., \& Larijani, R. (2011). The relationship between dimensions of anger and aggression in contact and noncontact sports. Social and Behavioral Sciences, 30, 247-251.

Aidar, F. J., Jacó de Oliviera, R., Chilibeck, P. D., de Souza, R. F., Carneiro, A. L., \& Machado-Reis, V. (2018). A randomized trial of the effects of an aquatic exercise program on depression, anxiety levels, and functional capacity of people who suffered an ischemic stroke. Journal of Sports Medicine and Physical Fitness, 58, 1171-1177.

Ali, K., Aseem, A., \& Hussain, M. E. (2019). Anaerobic training and its effects on sleep quality, state, and trait anxiety in collegiate athletes. Sport Sciences for Health, 15, 453-461.

Allen, J. J., Anderson, C. A., \& Bushman, B. J. (2018). The General Aggression Model. Current Opinion in Psychology, 19, 75-80.

Anderson, C. A., \& Bushman, B. J. (2002). Human aggression. Annual Review of Psychology, 53, 27-51.

Anestis, M. D., Anestis, J. C., Selby, E. A., \& Joiner, T. E. (2009). Anger rumination across forms of aggression. Personality and Individual Differences, 46, 192-196.

Berkowitz, L. (1989). Frustration-aggression hypothesis: Examination and reformulation. Psychological Bulletin, 106, 59-73.

Besharat, M. A., \& Ghiabi, B. (2012). Anger and aggression in contact and non-contact sports. Comprehensive Psychology, 1, 1-7.

Boostani, M. A., \& Boostani, M. H. (2012). Investigation and comparing aggression in athletes in non-contact (swimming), limited contact (karate) and contactable (kickboxing) sport fields. Journal of Combat Sports and Martial Arts, 3, 87-89.

Bostani, M., \& Saiiari, A. (2011). Comparison emotional intelligence and mental health between athletic and non-athletic students. Procedia - Social and Behavioral Sciences, 30, 2259-2263.

Buss, A. H., \& Perry, M. (1992). The aggression questionnaire. Journal of Personality and Social Psychology, 63, 452-459.

Caron, S. L., Halteman, W. A., \& Stacy, C. (1997). Athletes and rape: Is there a connection? Perceptual and Motor Skills, 85, 1379-1393.

Chandler, S. B., Johnson, D. J., \& Carroll, P. S. (1999). Abusive behavior of college athletes. College Student Journal, 33, 638-645.

Cho, S., Choi, H., \& Kim, Y. (2019). The relationship between perceived coaching behaviors, competitive trait anxiety, and athlete burnout: A cross-sectional study. International Journal of Environmental Research and Public Health, 16, 1424

Conroy, D. E., Silva, J. M., Newcomer, R., Walker, B. W., \& Johnson, M. S. (2001). Personal and participatory socializers of the perceived legitimacy of aggressive behavior in sport. Aggressive Behavior, 27, 405-418.

Egawa, J., Hochi, Y., Iwaasa, T., Togashi, E., Inaba, K., \& Mizuno, M. (2020). The effects of university students' physical activity experience on communication skills and anxiety. In R. Goossens \& A. Murata (Eds.), Advances in Intelligent Systems and Computing (Volume 970, pp. 358366). Cham, Switzerland: Springer.

Fabio, R. A., \& Towey, G. E. (2018). Cognitive and personality factors in the regular practice of martial arts. Journal of Sports Medicine and Physical Fitness, 58, 933-943.

Filho, M. G. B., Ribeiro, L. C. S., \& Garcia, F. G. (2005). Comparison of personality characteristics between highlevel Brazilian athletes and non-athletes. Revista Brasileira de Medicina do Esporte, 2, 114-118.

Fletcher, R., \& Dowell, L. (1971). Selected personality of high-school athletes and non-athletes. Journal of Psychology, 77, 39-41.

Gill, D. L., \& Williams, L. (2000). Psychological dynamics of sport and excercises. Champaign, IL: Human Kinetics.

Gümüșdağ, H. (2013). The influence of trait and state competitive anxiety on aggression: A study on professional football players. International Journal of Academic Research, 5, 188-192.

Healey, L. V., Holmes, V., Curry, S., Seto, M. C., \& Ahmed, A. G. (2019). Self-reported dysfunctional anger in men and women at a psychiatric outpatient clinic. Journal of Rational-Emotive \& Cognitive-Behavior Therapy, 37, 395-410.

Keeler, L. A. (2007). The differences in sport aggression, life aggression and life assertion among adult male and female collision, contact and noncontact sport athletes. Journal of Sport Behavior, 30, 57-76.

Kerr, J. H. (1999). The role of aggression and violence in sport: A rejoinder to the ISSP Position Stand. Sport Psychologist, 13, 83-88.

Khan, M. J., Fazaldad, G., Waheed, A., \& Arif, H. (2017). Level of aggression among athletes and non athletes. Shield, 12, 30-39.

Kotarska, K., Nowak, L., Szark-Eckardt, M., \& Nowak, M. (2019). Selected healthy behaviors and quality of life in people who practice combat sports and martial arts. International Journal of Environmental Research and Public Health, 5, 875. 
Kunimatsu, M. M., \& Mersee, M. A. (2012). Examining the presence of anxiety in aggressive individuals: The illuminating role of fight-or-flight mechanisms. Child \& Youth Care Forum, 41, 247-258.

Kuśnierz, C., Cynarski, W. J., \& Litwiniuk, A. (2014). Comparison of aggressiveness levels in combat sports and martial arts male athletes to non-practising peers. Archives of Budo, 10, 253-260.

Lazarus, R. S. (2000). Toward better research on stress and coping. American Psychologist, 55, 665-673.

Lee, Y., \& Lim, S. (2019). Effects of sports activity on sustainable social environment and juvenile aggression. Sustainability, 11, 2279.

Malinauskas, R., Dumciene, A., \& Malinauskiene, V. (2014). Perceived characteristics of aggressiveness in male adolescent athletes and nonathletes. Revista de Cercetare si Interventie Sociala, 45, 17-30.

Mladenović, M., Lazarević, P., Trunić, N., Bogavac, D., \& Živković, M. (2016). Differences in personality features and achievement motivation in child athletes and non-athletes. Journal of Physical Education and Sport, 14, 415-425.

Neumann, I. D., Veenema, A. H., \& Beiderbeck, D. I. (2010). Aggression and anxiety: Social context and neurobiological links. Frontiers in Behavioral Neuroscience, 4, 12.

Pett, M. A. (1997). Nonparametric statistics for health care research: Statistics for small samples and unusual distributions. Thousand Oaks, CA: Sage.
Pierce, C. A., Block, C. A., \& Aguinis, H. (2004). Cautionary note on reporting eta-squared values from multifactor ANOVA designs. Educational and Psychological Measurement, 64, 916-924.

Reynes, E., \& Lorant, J. (2001). Do competitive martial arts attract aggressive children? Perceptual and Motor Skills, 93, 382-386.

Ruisel, I. (1980). Dotazník na meranie úzkosti a úzkostlivosti: príručka [Anxiety state and anxiety trait questionnaire]. Bratislava, Slovakia: Psychodiagnostika.

Slepička, P., Hošek, V., \& Hátlová, B. (2009). Psychologie sportu [Sport psychology]. Prague, Czech Republic: Karolinum.

Spielberger, C. D., Gorsuch, R. L., \& Lushene, R. E. (1970). Manual for the State-Trait Anxiety Inventory. Palo Alto, CA: Consulting Psychologists Press.

Stewart, S. H., Taylor, S., \& Baker, J. M. (1997). Gender differences in dimensions of anxiety sensitivity. Journal of Anxiety Disorders, 11, 179-200.

Trulson, M. E. (1986). Martial arts training: A novel "cure" for juvenile delinquency. Human Relations, 39, 1131-1140.

Wyckoff, J. P. (2016). Aggression and emotion: Anger, not general negative affect, predicts desire to aggress. Personality and Individual Differences, 101, 220-226.

Ziaee, V., Lotfian, S., Amini, H., Mansournia, M. A., \& Memari, A. H. (2012). Anger in adolescent boy athletes: A comparison among judo, karate, swimming and nonathletes. Iranian Journal of Pediatrics, 22, 9-14. 